\title{
A Study on Change Management and Employees Performance in IMS
}

\author{
${ }^{1}$ Yu Hai Yun \\ ${ }^{1}$ School of Management, Harbin Institute of Technology, P.R.China, 150001. \\ 1yuyun4533@ hotmail.com
}

\author{
Article Info \\ Journal of Journal of Enterprise and Business Intelligence (http://anapub.co.ke/journals/jebi/jebi.html) \\ Doi: https://doi.org/10.53759/5181/JEBI202101006 \\ Received 28 August 2020; Revised form 15 September 2020; Accepted 16 December 2020. \\ Available online 05 January 2021. \\ (C2021 Published by AnaPub Publications.
}

\begin{abstract}
The result or outcome of an entity for its deliberate operational success is the outcome or outcome of an institution with regard to the desired objectives and targets. Operational output the study utilizes the analytical data collection process. For analysis, though, it will use both primary and secondary information. The main statistics is information that the author gathers through surveys or questionnaires and the secondary data is the data collected from prior studies and research. The study examined the effect of change management on the quality of workers, taking into account many factors such as ethics, productivity, morale and interaction among others. The research findings have shown that the greater the integrity of workers and the better the interaction, the higher the productivity and the lower the attrition. The study analyzed the impact of change management on employees' performance, taking into account many factors such as organizational ethics, recruitment, morale and interaction. The research results demonstrate that the higher the moral and communication standards of employees are at work, the greater the retention and the lower the turnover.
\end{abstract}

Keywords - Communication; Employee Morale; Employees Retention; Employee Turnover; Change Management Implementation; Information Management System.

\section{INTRODUCTION}

The outcomes or achievements of the organisation with respect to the aims and goals expected are known as operational efficiency [1]. In other words, the ability of the organization to meet its targets effectively and efficiently is organizational performance. The understanding of the organization's success against its rivals is very relevant for both staff and management and what improvements should be made to ensure they retain a competitive advantage on the market. Top managers find it difficult to implement transitions if they do not have the requisite skills and experience and this can have a negative effect on operational efficiency. Previous literature has shown that organizational performance is a comprehensive and complex concept and that the results required are to be achieved. Better performance means that the work is carried out efficiently and effectively. Corporate success relates to a lengthy period of time by organizations to resolve problems within and outside of the work environment so they can efficiently and effectively accomplish their goals. A [2] has shown that corporate success depends on achieving goals by transforming organization's inputs into outputs.

\section{Problem of the Study}

The retail sector recently suffered from a performance fluctuation and the main reason for the fluctuation is that the resignation of high levels of workers is a consequence of the introduction of evolving management practices without the requisite workforce preparation. Employees therefore resist change and leave. There are, however, other explanations why workers regret improvements, including the lack of technological ability, fear of the uncertain, reorganization, lack of communication and many more. The following section will therefore deal slightly with the aims of the study.

\section{Importance of the research}

The main objective of this analysis is to examine the impact on the performance of workers in the field of change management, taking the market as a case study into account.

- To analyze the effect of interaction on transition implementation

- Analysis of the effect on change implementation of workplace ethics 
- Analysis of the influence on change adoption of employee retention.

- Research the effect on transition execution of employee turnover.

Nonetheless, the descriptive approach is used for data collection by circulating in the retail sector questionnaires for over 100 respondents. The results will be analyzed with the SPSS analytical method to test conclusions in order to study the impact on employee performance of change management

\section{Resistance to change}

The reaction of employees to the change introduced by the institution results from resistance to change. The primary reason why most of the improvements are not effective or enforced is known. Many workers may give up looking for better opportunities because they refuse to change because they cannot respond to change and this is a critical aspect in the execution of the change management plan. This is crucial. A survey of 300 American companies exchanging insights and experiences in the management of transition. Research had shown that transition from top managers to small workers can be avoided at all grades.

\section{Employee efficiency}

The performance of an employee in a competitive environment is important to the survival of each company. Organizations also need trained and professional workers to be able to effectively and efficiently achieve their strategic targets.

\section{Loss of loyalty}

Organizations that provide products such as the banking sector have a propensity to spend more in their human capital to establish and sustain long-term relationships with their staff. Nevertheless, the decrease in employee performance and the rising number of outsourcing organizations. In fact, changing company positions and time constraints often affect workers ' working lives. Nevertheless, companies face several obstacles and need to make more effort to improve the performance of workers. Nonetheless, supervisors need to engage workers and encourage them to agree about their positions in the work place so that they can achieve the desired results. The policy means that workers consider their employment better suited for their interests, abilities and beliefs.

\section{Mental stress}

Organizational change can result in an increase in employee stress if awareness levels on the workplace are insufficient. Nonetheless, there are many causes for anxiety, including inequality, lack of communication between leadership and staff and the fear of the future. There are many explanations for pressure.

Loss of loyalty

Many businesses focus on reducing wages and benefits to boost cost savings. When a project of this kind is implemented, other employees leave the company and are finding a safer and healthier environment. Many citizens will nevertheless never give up because they are not able to find a job or just because they can't find a job anywhere. Enhanced time off: implementation of structural change, and particularly contraction. The first group includes staffs who want to control their prospects and the second group comprises employees who want to leave before the change occurs. The first group to track the future operates most efficiently, reaches expectations and shows that managers take responsibilities for and are able to handle the adjustments. The second group does not cope with a transition and will pursue other acts, such as late work, later lunchtime, late employment and much more. The second group does not comply with a transformation.

\section{Life changes}

Most structural changes require radical transformation which leads to work separation. Some of the reforms that have negative consequences to employees ' productivity include increasing salaries, eliminating healthcare, diminishing jobs and shifting to other cities and countries. These can be significant changes for employees and, in particular, those who support their families. The best way to manage these shifts is to preserve the ethical of workers and improve communication and understanding between employees and managers. It helps the worker to feel safe and not afraid of the unknown future.

\section{Application of Change Results within Companies}

The application of Change has an effect directly on the organization and its staff, relating to [3] study. This could lead to a loss of security and comfort and could negatively affect employee performance. Change is usually resisted by staff [4]. "There is no change in a healthy system, since life of a living system depends on its ability to establish a stable 
state" [15]. The [16] indicated that a resistance to change would contribute to many problems at work including avoidance and accomplishment of corporate growth goals.

Aversion is considered a normal response to change. Anxiety is the primary cause of resistance and the impairment of a desired position or duty is a result of [17]. He found that leaders that continue to react negatively to transition appear to have a negative impact on the company. Implementation of improvements may increase anxiety in the workplace of employees [5]. The impact of change affects the manner in which employees are concerned. Bureaucratic procedures are regarded as a form of social protection with respect to [19]. Since leaders are protected against anxiety in such systems through layers of Subordinate tests that distinguish them [20]. He demonstrated that the mechanisms of social security were designed to mitigate anxieties.

\section{Employee Moral}

It was shown that the change management process would lead to anxiety and aversion to workforce transition as most workers dread from the future, and this is why it is not important for the employees to improve their workplace. Such actions take place in a climate where there is no interaction and accountability in the corporate environment, leading to high pressure among workers, which can adversely affect their morale and thus influence the overall financial success of the company [6]. Change management can also influence the ethical of workers at work and the retention of staff. Employee morale is also an indicator of job satisfaction, which implies that workers are happy with the working environment, working conditions and working procedures, to be successful and to optimize their corporate achievement. Earlier research has shown that organizations that have inconsistent transitions and lack of communication can reduce employee satisfaction, and incurring programs that use the micromanagement methodology to workers tend to increase stress levels and thus impact performance [7]. As previously explained, pressure is viewed as an important factor which directly affects workplace ethics.

For example, the Telkom Group, identified as the Web Power, made theoretical calculations of efficiency without including workers in such decisions [8]. The administrative adjustment accompanied by a shift in the weighing process was introduced. Such reforms raised technicians 'stress levels when job became overwhelmed, leading to people leaving the company and reducing overall performance [21]. It is apparent from the above that the connection between job satisfaction, workplace ethics and management of transition is strong. From a management standpoint, the institution should function properly on implementing desired methods to decide while practicing workplace change [23].

The key objectives behind these concepts are to provide an analysis of how evolving management practices have an impact on the employee quality and how they can lead to job satisfaction. King research [24] showed that the Hygiene theory of Herzberg motivation is the first theory aimed at investigating factors that directly influence employee satisfaction. Herzberg's work is planned to explore the interests of its workers [9]. The attributes of happiness with the job included appreciation, accomplishment, development and commitments and advancement. Herzberg found the above characteristics to be workplace motivators [10].

It also identified, however, certain causes linked to workplace discontent and included management, interpersonal relations, corporate policy and administration and were stated as aspects of hygiene [11]. The theory of Hertzberg is the foundation of enrichment of jobs. Referring to a study [26], improved function aims at altering a job where a worker is given the opportunity to understand how he or she can accomplish, recognize and improve his or her profession. Hertzberg's concept offers managers a more detailed description, and increases worker social happiness at work by ensuring the employee feels secure in his workplace. The theory of Maslow was focused on the experience about human behaviour. Maslow suggested that motivation consists of five fundamental needs which are physiology, security, love, appreciation and updating [12].

Physiologic: this includes basic conditions including meat, air and water. These criteria are described as follows. Safety: includes the requirements that ensure safety for staff on the workplace• Love: includes belonging and affection needs.

Esteem: covers the needs of the people in the workforce and community for a credibility, respect and appreciation.

Self-Update: self-performance urge. This ensures that you can become the strongest person.

When the desires are met, it lacks the motivating power in relation to Maslow's principle. Therefore, administrators should establish strategies that recognize the interests of workers in the work place and inspire their personnel [13]. Maslow's principles also seek to improve the perception of job satisfaction in the workforce and are designed to introduce an organization's change management strategy, to integrate staff input at the outset of the transition [14]. 


\section{Staff Turnover}

He confirmed that job dissatisfaction is one of the key factors leading to high turnover, referring to the [27] study. The work focuses on the idea that, when output at the job is decreased, employees maintain more. Research [18] found that many companies are more concerned about the sales of employees because it has a huge impact on their businesses. [25] is focused on occupational stress research which drives workers out of work and adversely affects company outcomes. The results of the research show that the management does not understand the value of restructuring because it is called the secret costs and not included in the financial statements. Management of resignation: the costs of paying employees to seek termination payments are borne [27]: It also includes the costs of ensuring that human resources reports are completed on time.

Selection fees, including advertising and Testing Center charges: these include support from a recruiting agency to compensate for the selection of the candidate with a fee of a customer. Recruitment and training costs: can be measured for recruitment in keeping with the organizational duration. Custody expense during the turnover period: it is difficult to immediately substitute staff, so time is needed. In this scenario, the company will supplement its workers on the job with internal resources. Recruitment administration and selection process: such costs include the recruitment and selection process by the Human Resources department. Potential hire inductive recruitment: The training of a potential worker is seen as more costly than increasing the existing employee's salary. It is therefore better to keep skilled and future employees at work by indemnifying them instead of switching them to new staff, which would result in time and money costs. The cost of reduced productivity during vacancy training: When a candidate is recruited, the performance gap will remain for a certain time until the person can complete the tasks required.

\section{The Role of Leadership in the Implementation and Communication of Change Management}

The leading role in change is important, although many domestic and external factors could influence the change in the workplace and affect the performance of the organization. It is therefore important to clarify that the organisation is in the midst of the programs for transition. The Path Goals Theory is one of the most important leadership approaches, [21]. The [21] developed this concept and is seen as a leadership template. The importance of this theory is that it is the leader's role to help employees attain their objectives and provide the guidance necessary for the employees to align their objectives with organisation.

The word target purpose stems from the idea that managers articulate the way to help workers achieve their goals through moving for their ambitions at work and by simplifying the road across their career paths through barriers. The theory suggests that the actions of rulers will not work without the necessary resources at work. Accorder management will lead to a greater degree of work satisfaction in the workplace, thereupon reducing employee turnover, according to [22], predictions based on path-goal theory. Supportive management may contribute to the high performance and happiness of workers in carrying out specific tasks. Internally controlled employees tend to be more satisfied with their participation in the workplace. The aspirations of workers would increase if they know there is a sense of performance at work. Such finding is based on the fact that when leadership is carried out in the workforce, the performance and morale of workers continue to be favorably influenced.

\section{Change in Technology on Employee Performance}

In [23] study on technological change and the effect on increased workforce efficiency, using evidence from 13 nations. The findings have shown that technological changes will improve the efficiency of workers and increase performance when integrated effectively and efficiently with other tools. In other words, using technology ethically can improve the productivity of employees. Enhancing the quality and operational efficiency of our workers would render technical progress effective and productive. By learning, citizens can acquire new skills and development skill. Referring to a [24], technological change has a significant impact on the performance of workers, since it is a key factor in enhancing organizational efficiency. The bulk of the studies found that technological improvements and efficiency are in positive correlation, concluding that technological advances are essential to the success of workers.

Departments of research and development are built to allow companies to deal with technological change. In [28] exposed the direct link between technological changes and physical conditions with how significant changes could be made and thus influence the level of performance of their workers. We also shown that technological changes in their work entitled technological change and workers ' productivity have a positive impact on working people's results if they are handled efficiently and effectively. This is directly relevant to managing and responding to external factors in the internal control systems. The use of new technology has shown increased performance, efficiency and production.

\section{METHODOLOGY}

The methods used by the data gathering author will be explored briefly in this chapter of the study. This chapter further address the study parameters, test models, conceptual model and describes the statistical tools for collecting 
data. There are two forms of methods which are empirical and subjective. The statistical approach is a tool used to collect data by spreading questionnaires over a certain number of participants of 50. Using SPSS statistical tools, the data is collected and analyzed for empirical validation of study findings. With respect to the qualitative approach, information is collected by detailed interviews with a few respondents. The inquiry will use the analytical data collection process. In research, however, both primary and secondary data are used. The primary information was provided by the author himself through interviews or questionnaires, and the secondary data is collected via earlier research and studies.

\section{Variables of research}

Two types of variables, which are dependent and independent variables, will be used in research.

Change implementation is the dependent variable.

The independent variables are: rotation, retention, moral and communication of employees.

The analysis hypotheses will be constructed on the basis of the above variables.

\section{RESEARCH HYPOTHESES}

This section of the thesis addresses briefly the techniques used by the data collection researcher. This chapter discusses further the parameters, test models, and the conceptual model of the study.

\section{Methodology for study}

There are two types of quantitative and qualitative methodologies. The statistical approach is a device used by a group of 50 respondents for data collection through disseminating questionnaires. Data are collected and analyzed using SPSS analytical instruments to verify study results empirically. Comprehensive conversations with a few participants collect information about the subjective method. The questionnaire uses the process of collecting analytical data. But both primary and secondary information are used in analysis. Previous research and studies also given the researcher himself the primary details by interviews or questionnaires and the secondary data.

\section{Conclusion}

This research focused on the methods used to collect data. The questionnaires are based on the research variables and distributed for data collection among the respondents. The data collected shall be analyzed with the analytical method SPSS to evaluate the data and test theories of the study.

\section{Data Analysis}

The information will be evaluated using SPSS and the assumptions will be tested and the findings interpreted based on this study.

\section{Regression Analysis}

Table 1: Communication and Change Implementation Regression Model Summary

\begin{tabular}{|l|r|r|r|r|}
\hline Model & \multicolumn{1}{|c|}{$\mathrm{R}$} & $\mathrm{R}$ Square & \multicolumn{1}{c|}{$\begin{array}{c}\text { Adjusted R } \\
\text { Square }\end{array}$} & $\begin{array}{c}\text { Std. Error of the } \\
\text { Estimate }\end{array}$ \\
\hline 1 & $.920^{\mathrm{a}}$ & .847 & .846 & .43263 \\
\hline
\end{tabular}

a. Predictors: (Constant), Communication

Coefficients

\begin{tabular}{|c|c|c|c|c|c|c|}
\hline \multirow{2}{*}{\multicolumn{2}{|c|}{ Model }} & \multicolumn{2}{|c|}{ Unstandardized Coefficients } & \multirow{2}{*}{$\begin{array}{c}\begin{array}{c}\text { Standardized } \\
\text { Coefficients }\end{array} \\
\text { Beta } \\
\end{array}$} & \multirow[t]{2}{*}{$t$} & \multirow[t]{2}{*}{ Sig. } \\
\hline & & $\mathrm{B}$ & Std. Error & & & \\
\hline \multirow{2}{*}{1} & (Constant) & .417 & .111 & & 3.757 & .000 \\
\hline & Communication & .982 & .042 & .920 & 23.305 & .000 \\
\hline
\end{tabular}

a. Dependent Variable: Change Implementation

Source: Author Data Collection

Referring to table 1, the regression analysis aimed to assess the relation entre dependent and independent variables, the above regression model had been applied and hypothesis will be evaluated on the basis of the test results [28]. The 
results indicate an importance level below 0,00, which means that the zero hypothesis that "There is a negligible correlation between communication and change implementation" is rejected and the alternative hypothesis, that "There is a negligible correlation between communication and change implementation," is accepted. There is a non-important correlation between communication and change implementation. The R-square ratio refers to the above test and indicates an $84.7 \%$ ratio that is above $25 \%$. Therefore, the analysis parameters are closely interrelated.

Table 2: Staff turnover and change implementation regression

\begin{tabular}{|l|r|r|r|c|}
\hline Model & \multicolumn{1}{|c|}{ R } & R Square & $\begin{array}{c}\text { Adjusted R } \\
\text { Square }\end{array}$ & $\begin{array}{c}\text { Std. Error of the } \\
\text { Estimate }\end{array}$ \\
\hline 1 & $.959^{\mathrm{a}}$ & .919 & .918 & .31528 \\
\hline
\end{tabular}

a. Predictors: (Constant), Staff Turnover

\begin{tabular}{|c|c|c|c|c|c|c|}
\hline \multicolumn{7}{|c|}{ Coefficients } \\
\hline \multirow{2}{*}{\multicolumn{2}{|c|}{ Model }} & \multicolumn{2}{|c|}{ Unstandardized Coefficients } & \multirow{2}{*}{$\begin{array}{c}\text { Standardized } \\
\text { Coefficients } \\
\text { Beta } \\
\end{array}$} & \multirow[t]{2}{*}{$\mathrm{T}$} & \multirow[t]{2}{*}{ Sig. } \\
\hline & & $\mathrm{B}$ & Std. Error & & & \\
\hline \multirow{2}{*}{1} & (Constant) & .012 & .089 & & .134 & .03 \\
\hline & Staff Turnover & 1.022 & .031 & .959 & 33.305 & .000 \\
\hline
\end{tabular}

a. Dependent Variable: Change Implementation

Source: Author Data Collection

Referring to table 2, the regression analysis aimed to estimate the relationship between dependent and separate variables, the above regression model was practiced; the hypotheses are tests on the basis of test results. The outcome was a validity rate of 0.03 that is less than 0.05 and this implies it does not support the null hypothesis that "The association between employee turnover and improvements is negligible," and supports the alternative hypothesis that "There is an insignificant connection between employee turnover and shift implementation." The R-Square ratio indicates a ratio of $91.9 \%$, more than $25 \%$, with reference to the above test. Therefore, between the analysis parameters there is a strong correlation.

Table 3: Moral and Change Implementation regression

\begin{tabular}{|c|c|c|c|c|}
\hline Model & $R$ & R Square & $\begin{array}{c}\text { Adjusted } \mathrm{R} \\
\text { Square }\end{array}$ & $\begin{array}{c}\text { Std. Error of the } \\
\text { Estimate }\end{array}$ \\
\hline 1 & $.937^{\mathrm{a}}$ & .878 & .876 & .38694 \\
\hline
\end{tabular}

a. Predictors: (Constant), Moral

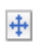

\begin{tabular}{|c|c|c|c|c|c|c|}
\hline \multicolumn{7}{|c|}{ Coefficients } \\
\hline \multirow{2}{*}{\multicolumn{2}{|c|}{ Model }} & \multicolumn{2}{|c|}{ Unstandardized Coefficients } & \multirow{2}{*}{$\begin{array}{c}\text { Standardized } \\
\text { Coefficients } \\
\text { Beta }\end{array}$} & \multirow[t]{2}{*}{$\mathrm{T}$} & \multirow[t]{2}{*}{ Sig. } \\
\hline & & B & Std. Error & & & \\
\hline \multirow{2}{*}{1} & (Constant) & .372 & .099 & & 3.740 & .001 \\
\hline & Moral & 1.008 & .038 & 937 & 26.523 & .000 \\
\hline
\end{tabular}

a. Dependent Variable: Change Implementation

Source: Author Data Collection 
Referring to table 3, the regression analysis aimed to evaluate relations between the dependent and independent variables, the above-noted regression model has been used and hypotheses are tested based on test findings. The results showed that 0.00 was below 0.05 , which implies that the null hypothesis that "The moral and switch execution are irrelevant in connection is dismissed" was not appropriate, and that the alternate hypothesis that "There is a marginal association between moral and increasing implementation" was embraced. The R-Square ratio indicates a ratio of 87.8 percent higher than 25 percent for the above study. There is therefore a strong correlation between the variables of research [29].

Table 4: Retention and change implementation regression Model Summary

\begin{tabular}{|l|r|r|r|c|}
\hline Model & \multicolumn{1}{|c|}{$\mathrm{R}$} & $\mathrm{R}$ Square & \multicolumn{1}{|c|}{$\begin{array}{c}\text { Adjusted } \mathrm{R} \\
\text { Square }\end{array}$} & $\begin{array}{c}\text { Std. Error of the } \\
\text { Estimate }\end{array}$ \\
\hline 1 & $.981^{\mathrm{a}}$ & .961 & .961 & .21734 \\
\hline
\end{tabular}

a. Predictors: (Constant) Retention

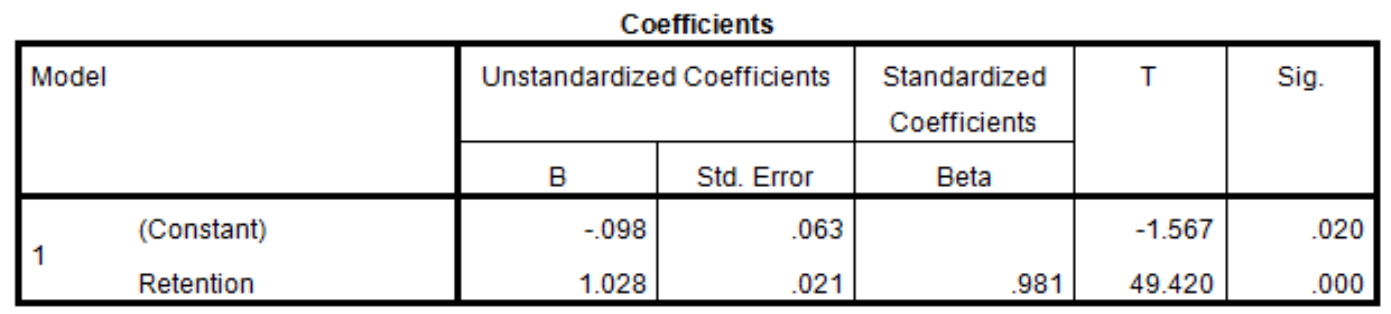

a. Dependent Variable: Change Implementation

Referring to table 4, the regression analysis aimed to assess the association between contingent and independent variables it is used to analyze this regression model and the predictions are assessed on the basis of the test results. The findings show a significant 0,00 point, lower that of 0,05 , i.e. the inability to consider the zero hypothesis that the retention and change execution is insignificantly correlated and that the alternative hypothesis that the retention and the transition implementation are insignificantly correlated is adopted. The R-square equation indicates a proportion of 96.1 percent higher than 25 percent in comparison to the check above. There is thus a strong correlation between the variables in analysis.

\section{Hypotheses Testing}

H1-0: There is a negligible correlation between communication and change implementation: the following section will deal with the testing hypotheses based on the collected data. H1-0:

H1-1: Communications and introduction of transition are strongly associated.

$\mathrm{H} 2-0$ : There is a slight association regarding workers 'retention and the introduction of reforms is dismissed.

H2-1: The employee turnover is substantially linked and adjustments are acknowledged.

H3-0: The connection between ethics and the adoption of reform is negligible.

H3-1: A significant correlation exists between the application of ethics and improvement.

H4-0: The link between maintenance and adoption of transition is negligible. H4-0:

H4-1: The maintenance and execution of improvements are considerably associated.

\section{Main Findings}

The study has shown that interaction, ethics, recruitment, attrition and transition are closely related. Nevertheless, the more interaction between employees and managers takes place, the more they can cope with and not fight the transition in the workplace. Research have shown that supermarket companies, which use contact on a daily basis, appear to be more likely than entities that do not implement change to deal with changes. The stronger the principle of the worker, the better the willingness to cope with transition. The results showed that organizations with a poor moral standard tend to oppose change than employees with a high moral standard. Nevertheless, interaction and increase in the productivity of workers tend to keep staff at work and minimize the risk of employee turnover. People tend to resist change because they fear that they are heading to an unknown future and that for numerous reasons they can risk 
their jobs. One is that they may not have the requisite skills to deal with transition. It is therefore the responsibility of managers to cope with transition and to enhance the ethics of workers, and this can be done through interaction means.

\section{CONCLUSION}

This chapter analyzed the research hypotheses, which were collected and validated. In this section, the key restrictions confronting the investigator and guidelines for increasing the study rate in further studies are discussed. The research examined the impact of change management on the performance of employees, including employee morality, retention, turnover and communication, with a focus on several indicators. The research found that, as the moral and communication of the employees are higher in the workplace, the greater the retention and the lower the turnover. The workers thus tend to resist reform, as they fear the future perhaps because of their lack of the necessary skills or because they are unable to use new technology to be applied on the job.

\section{Limitations}

Many of the restrictions have been met and the following are listed:

- Research is considered to be broad aspects and therefore all its details cannot be dealt with in this research.

- The survey presented is known as small.

- Limited time limitations, which prohibited the author from approaching any retail agency.

- Study only included some retail shops, perhaps if the results of the study were replicated in another market.

- Only a single inferential numerical method has been implemented, due to time constraints.

- Due to issues regarding privacy, some participants refused to answer questions.

\section{Recommendations}

Implementing the following in future studies is highly recommended:

- Addressing new variables.

- Specified retail stores that can reach a greater number of respondents with several branches.

- Implement quantitative as well as qualitative methods.

- Add new questions to study the impact of change management on employees' performance.

- Address new research variables.

- Implement several statistical tools to study the correlations among the variables.

All these if implemented will add a value for the research in future studies, and will assist the organizations to minimize turnover and increase employee retention in the workplace by training employees to cope with change.

\section{References}

[1]. Z.G. Tang, X.J. Yang, Y.H. Chen, " The accounting industry to strengthen management of the basic way" Financial Observation, pp.55, 2008.

[2]. Y.L.Yu, "The development of accounting in new centry", Nankai business review.pp.22-26, 2000.

[3]. X.S.Zhou, "The Discussion on Accounting Model of Enterpris", Nankai business review.pp.52-56, 2000.

[4]. C.Z.Mou, "The western financial management status and private enterprise management mode is discussed", Research of Financial and Accounting. pp.38-40, 2004.

[5]. S.H.Jia, "Reviewing internal accounting control and improve the system construction proposal", Friends of Accounting.pp.48, 2005.

[6]. M.Wu, " On the Construction of Enterprises Internal Accountancy Control System", Journal of Hubei College of Finance and Economics," vol.15,pp.60-62,April25, 2003.

[7]. S.B. Si,S S.D.sun, G.C.Hang and J.Q.Wang, "A Weighted Analysis of an Integrated Logistics Support Based on Triangular Fuzzy Number", Journal of Northwestern Polytechnical University", vol.6, pp.689-694, 2004.

[8]. Ma Zhihan, "Construction market engineering quality management at home and abroad," Popular Science, vol.10, pp. 4-6, Octobor 2005.

[9]. Guo Handing, "A study of government administration and supervision of construction quality," Tianjing University, 2003.

[10]. Xu Bo and Wang Guoying, "Construction management system innovation outlook after joining the WTO," Construction and Architecture, vol.4, pp. 9-11, April 2003.

[11]. Zhang Qiaoling, "Research on construction quality assessment: model, methodology and mechanism," Tsinghua University, 2004.

[12]. Deng Jianxun and Zhou yi, "Construction engineering quality risk management model under insurance mechanisms," Architecture economy, vol. 3, March 2008.

[13]. A.H.Mowbray and Williams CA, "Insurance," 4th ed, New York: McGraw- Hill, 1995.

[14]. Martin Loosemore, "Crisis management in construction projects," Beijing: China Architecture and Building Press, 2003, pp.16-17.

[15]. Wang Zhuofu, "Project management: risk and response," Beijing: China WaterPower Press, 2005.

[16]. Xu Bo and Zhao Hongyan, "Construction quality insurance system and implementation in France," Construction and Architecture, vol.8, Agust 2004, pp.59-63.

[17]. S. M. Saad, "The reconfiguration issues in manufacturing systems", Journal of materials processing technology, vol. 138, no. 1, pp. 277$283,2003$.

[18]. D. Ye and D.C. Zhan, "Agility of enterprises and its metrics", China mechanical engineering, vol. 9, no. 4, pp. 21-23, 1998.

[19]. R. Z. Tang, D. J. Jia and W. L. Ren, "Study on agent-based architecture of reconfigurable SCM system", Journal of zhejiang university, vol. 38 , no. 10, pp. 1265-1269, Oct 2004. 
[20]. Y. T. Chai, X. D. Zhang and F. Y. Li, The research on agile information system Computer integrated manufacture system, vol. 5, no. 2, Apr 1999.

[21]. M. J. Rui, Management: modern perspectives, Shanghai People Publishing Company, vol. 39, 2005.

[22]. D. W. Wang, Agile ERP and its decision and optimization, Beijing, NJ:Machine manufacture publishing company, pp. $27,2003$.

[23]. L. M. Zheng, P. Yue and H. Ren, "Variable research on BMP pattern", Journal of guangdong university of business studies, no. 2, pp. 4657, 2005.

[24]. Q. Yu, Enterprise reconfigure: reorganize business process, Guangzhou, NJ:GuangDong Economic Publishing Company, pp. 30-34, 2000.

[25]. G. Runo and M. Orchiano, "Making CIMOSA operational: the experience with the prime objects tool", Computers in industry, vol. 40, no. 2-3, pp. 279-291, 1999.

[26]. K. Kosanke and M. Zelm, CIMOSA modelling processes Computer in industry, vol. 40, pp. 141-153, 1999.

[27]. T. He, D.C. Zhan, X.F. Xu and P. Wang, "Research on standardization of function components of NERP system", Computer integrated manufacture system, vol. 10, pp. 177-182, Dec 2004.

[28]. B. Scholz-Reiter and E. Stickel, Business process modeling, Berlin:Springer, 1996.

[29]. Y. T. Chai, X. D. Zhang and F. Y. Li, "Research on the reconstructivity of Agile Supply Chain Management System Journal of Tsinghua University", vol. 40, no. 3, pp. 68-71, 2000. 